\title{
Myogenic Response in Large Pulmonary Arteries and Its Ontogenesis
}

\author{
JAQUES BELIK \\ Departments of Pediatrics and Physiology, The University of Manitoba, Winnipeg, \\ Manitoba, Canada
}

\section{ABSTRACT}

To evaluate the myogenic response and its ontogeny in large pulmonary arteries, we studied 45 newborn and 30 adult guinea pigs. Compared with the those of the adult, the newborn arterial vessels possessed a significantly $(p<$ $0.01)$ smaller diameter $(1153 \pm 34$ versus $1656 \pm 65 \mu \mathrm{m})$, static compliance $(2.2 \pm 0.3$ versus $4.6 \pm 0.7 \mu \mathrm{m} / \mathrm{mN})$, and active stress $\left(3.4 \pm 0.4\right.$ versus $\left.5.8 \pm 0.7 \mathrm{mN} / \mathrm{mm}^{2}\right)$. Stretchinduced contraction was obtained by quick stretch of the vessel segments to $120,140,160,180$, or $200 \%$ of their optimal length, and the myogenic response was measured as the change in force after muscle relaxation with papaverine. A myogenic response was observed in $94 \%$ of the newborn and $93 \%$ of adult vessel segments, and significant age differences in the response were present. The magnitude of the active force generated for any stretch over $120 \%$ was significantly greater in the newborn $(p<0.01)$, and as a percentage of $\mathrm{K}^{+}(127 \mathrm{mM})$ stimulation, a 2 -fold

Vessels respond to an increase in intraluminal pressure with vasoconstriction. This phenomenon, called the myogenic response or stretch-induced contraction, was originally described by Bayliss in 1902 (1). Previous data on in vitro vessel segments and in vivo organ perfusion studies of several animal species have confirmed its existence in a variety of systemic vessels (2-7). The phenomenon is most prevalent in small resistance units, and this has led to the current belief that the myogenic response plays an important role in organ autoregulation of blood flow after arterial pressure changes (2).

Limited data are available on the myogenic response of lung vessels. In pulmonary allografts in the hamster, Davis et al. (8) were unable to observe any changes in arteriolar diameter after alterations in transmural pressure, whereas vasoconstriction was observed in systemic cheek pouch arterioles under similar conditions. To the best of our knowledge, the only other study of the myogenic response in pulmonary vessels was reported by

Received September 14, 1993; accepted February 25, 1994.

Correspondence: Dr. J. Belik, Women's Hospital, Room WR 004, 735 Notre

Dame Ave., Winnipeg, Manitoba, R3E OL8 Canada.

Supported by a grant from The Medical Research Council of Canada. stretch of the vessels' optimal length resulted in a force of $1073 \pm 159 \%$ in the newborn compared with $51 \pm 16 \%$ in the adult $(p<0.01)$. The myogenic response in these large pulmonary vessels was completely suppressed by a calcium channel blocker (D-600) but unaltered by addition of a nitric oxide synthase inhibitor $\left(\mathrm{N}^{\mathrm{G}}\right.$-methyl-L-arginine) or indomethacin. We conclude that the large pulmonary arterial vessels of the guinea pig exhibit a powerful stretchinduced myogenic response that is greater in the newborn period. Changes in vessel wall stiffness brought about by the myogenic response of large pulmonary arteries may play a role in the control of lung vascular resistance. (Pediatr Res 36: 34-40, 1994)
Abbreviations
L-NAME, $\mathrm{N}^{\mathrm{G}}$-methyl-L-arginine
PPHN, persistent pulmonary hypertension syndrome

Kulik et al. (9) in adult cats. Stretch of $<1000-\mu \mathrm{m}$ diameter feline pulmonary arteries by $100 \%$ of their resting length resulted in active force generation of the same magnitude as observed with high potassium stimulation. However, in vessels with diameters $>1000 \mu \mathrm{m}$, the myogenic response was absent.

Study of the myogenic response in large capacitance arteries has received little attention, in spite of the fact that large systemic arteries $(1,5,10-12)$ and veins (13) do exhibit stretch-induced contraction. This lack of interest is likely related to the unclear physiologic significance of the myogenic response in large vessels, inasmuch as they are not believed to participate in the control of vascular resistance. Yet, the large vessels' elastic properties are believed to play an important role in the maintenance of adequate downstream organ perfusion during diastole as well as to act as a buffer by reducing the pressure transmitted to the smaller resistance vessels. This phenomenon, known as the "Windkessel Effect" (14), clearly involves stretching of the vessel wall, the magnitude of which will depend on the overall compliance of the vessel segment.

Pressure sensing by the smaller arteries is an important regulator of vascular resistance because vessels respond 
to an increase in intravascular pressure with stretchinduced vasoconstriction. Thus, changes in the compliance of large proximal arteries, as a result of stretchinduced myogenic responses, could in fact alter the downstream pulmonary vascular resistance by virtue of transmitting higher pressures to the smaller resistance vessels. Age differences in either the magnitude of the myogenic response of the pulmonary large arteries or the vascular smooth muscle contraction-relaxation properties could also explain the poorly understood higher pulmonary vascular resistance of the neonatal period.

Albeit controversial, there is evidence that changes in the main pulmonary wall stress alters the pulmonary vascular resistance and that the magnitude of the response is age dependent. Juratsch et al. have shown that nonocclusive distension of the main pulmonary artery results in a significant increase in pulmonary vascular resistance in the dog (15-17) and sheep (18). Compared with the young and adult sheep, the increase in pulmonary vascular resistance was greatest in newborn sheep (18). Although the validity of these observations has been questioned $(19,20)$, in the newborn sheep the pulmonary vascular resistance remains elevated in some animals for up to $2 \mathrm{~h}$ after deflation of the arterial balloon (18). In addition, studies by Baylen et al. (21) in newborns with PPHN indicated that infants recovering from this syndrome exhibited the greatest increase in downstream pressure after nonocclusive balloon inflation of the main pulmonary artery.

These studies suggest age differences in the vascular stretch-induced contraction response and a potential role for the large pulmonary arterial vessels in controlling the pulmonary vascular resistance downstream. Thus, the purpose of the present study was to evaluate the presence and magnitude of stretch-induced myogenic response in the newborn and adult large pulmonary arteries.

\section{METHODS}

Forty-five newborn ( $<3 \mathrm{~d}$ of age) and 30 adult ( $>2$ mo of age) Hartley guinea pigs were studied. The animals were rapidly killed with an overdose of pentobarbital sodium (30 mg/kg, intraperitoneally) and ketamine hydrochloride $(20 \mathrm{mg} / \mathrm{kg}$, intraperitoneally). The chest was opened and the right and left second-generation extrapulmonary arteries (first branches of the main pulmonary artery external to the lung) were obtained and further dissected free of tissue in cold Krebs solution. Intact vessel segments $(2 \mathrm{~mm}$ in width) were mounted in a muscle bath, held at the bottom by a fixed rod, and suspended via a fine metal triangle and a silk thread (7.0) to a customized lever transducer system. Details of the lever system used have been previously published (22). The bath was filled with Krebs-Henseleit solution $(\mathrm{NaCl}$, 115; $\mathrm{NaHCO}_{3}, 25 ; \mathrm{NaHPO}_{4}, 1.38 ; \mathrm{KCl}, 2.51$; $\mathrm{MgSO}_{4} 7 \mathrm{H}_{2} \mathrm{O}, 2.46 ; \mathrm{CaCl}_{2}, 1.91$; and dextrose, $5.56 \mathrm{mM}$ ) maintained at $37^{\circ} \mathrm{C}$ and bubbled with $95 \%$ oxygen and $5 \%$ carbon dioxide. After a 60 -min incubation period, the vascular smooth muscle was subjected to a series of supramaximal electrical stimulations $(18 \mathrm{~V}, 12 \mathrm{~s}, 60 \mathrm{~Hz})$ at incremental preloads to determine its optimal length and maximal active tension according to standard techniques (22). The measurement of the muscle's optimal length under these conditions corresponds to the vessel segment diameter (resting length) at resting tension. All measurements of the muscle mechanical properties and myogenic response were obtained with the vessel segment at resting length. Stress was normalized to the vessel segment cross sectional area (resting length/wet weight), assuming a vessel wall density of $1.06 \mathrm{mg} / \mathrm{mL}$. The vessel width (axial length of the segment) and resting length were measured with the aid of a magnifying eyepiece and micrometer with an accuracy of $0.01 \mathrm{~mm}$. The single wall thickness $(\mathrm{mm})$ was calculated from the measurements of width $(\mathrm{mm})$, length $(\mathrm{mm})$, and tissue weight (mg) according to the formula: Thickness = weight/ (width $\times$ optimal length $\times 1.06$ ). Vessel wall static compliance was derived as the slope of the linear regression of length changes versus load necessary to achieve the new length. Measurements were obtained for lengths shorter than the optimal length during the initial determination of the muscle length-tension curve and for up to a $200 \%$ increase in optimal length. The latter measurements were obtained in the presence of papaverine $\left(10^{-4}\right.$ $\mathrm{M})$ in the muscle bath to avoid changes in compliance related to stretch-induced contraction. For all the newborn $(n=6)$ and adult $(n=6)$ pulmonary artery segments in which compliance was measured, the correlation coefficient of length changes versus load applied was greater than $0.9(p<0.01)$.

Myogenic response. To elicit the myogenic response, the vessel segments were rapidly stretched $(<3 \mathrm{~s})$ to either $120,140,160,180$, or $200 \%$ of their optimal length by subjecting them to a preset higher load. After each stretch maneuver, and when the force tracing was stable, complete muscle relaxation was induced by the addition of papaverine $\left(10^{-4} \mathrm{M}\right)$. The magnitude of the stretchinduced myogenic response was measured as the change in force brought about by papaverine relaxation (Fig. 1), as previously described by Hwa and Bevan (3). The myogenic response of each vessel was elicited only once, and its magnitude was expressed as a percentage of the maximum tension obtained after high potassium (127 $\mathrm{mM})$ stimulation. The effect of papaverine $\left(10^{-4} \mathrm{M}\right)$, at the above concentration, upon the newborn $(n=4)$ and adult $(n=4)$ pulmonary arterial smooth muscle resting tension was determined in pilot experiments. A representative tracing is depicted in Figure 1. The change in force after addition of papaverine $\left(10^{-4} \mathrm{M}\right)$ was $0.19 \pm 0.13 \mathrm{mN}$ for the newborn and $0.19 \pm 0.57 \mathrm{mN}$ for the adult vessels, a difference that was not statistically significant. In addition, papaverine $\left(10^{-4} \mathrm{M}\right)$ completely suppressed supramaximal electrical and high potassium stimulated force development.

Pharmacologic effects on myogenic response. To evaluate the role of extracellular calcium, endothelium-derived 


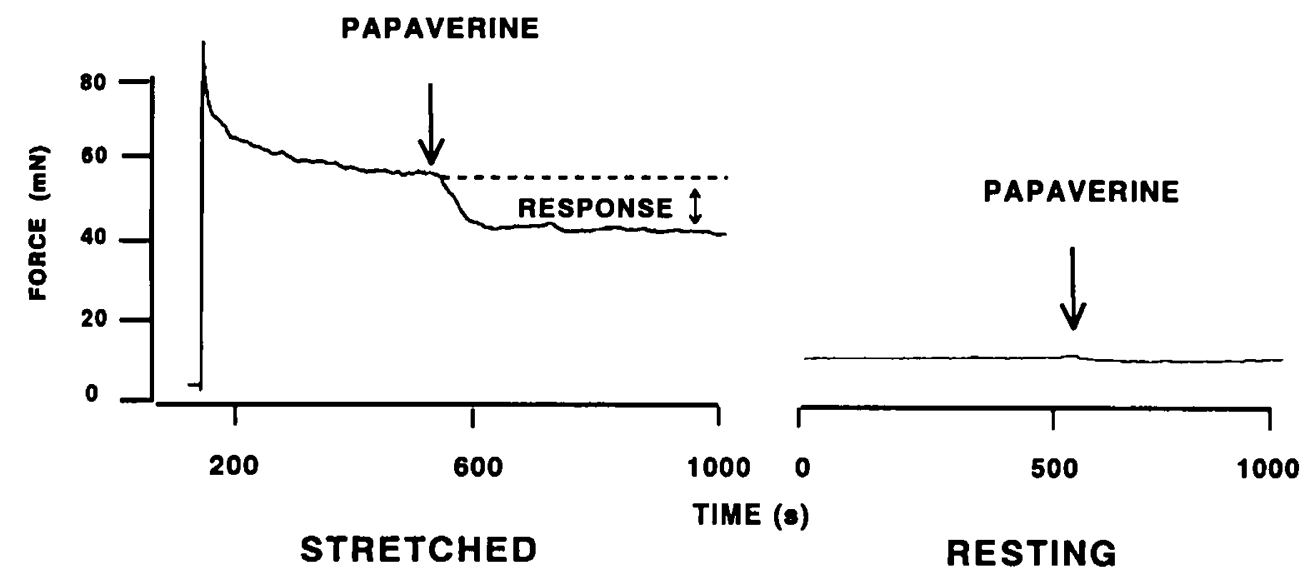

Figure 1. A typical stretch-induced contraction after a $160 \%$ stretch is shown in the left panel. Addition of papaverine $\left(10^{-4} \mathrm{M}\right)$ resulted in an immediate reduction in force. The magnitude of the myogenic response was measured as the reduction in force after papaverine administration. In the right panel, the same concentration of papaverine applied to the muscle at resting tension had no effect on the force.

nitric oxide, and prostaglandins on the myogenic response, we used the following drugs: the calcium channel blocker D-600 $\left(10^{-5} \mathrm{M}\right)$, the nitric oxide synthase inhibitor L-NAME $\left(10^{-5} \mathrm{M}\right)$, and the cyclooxygenase inhibitor indomethacin $\left(10^{-5} \mathrm{M}\right)$, respectively. All drugs were obtained from Sigma Chemical Co. (St. Louis, MO) and prepared fresh on the day of the experiment. To test for the effect of each of these drugs, newborn vessel segments were obtained as previously described and stretched to $160 \%$ of their optimal length in the presence and absence of the tested drug. The magnitude of the myogenic response was measured with the protocol previously described. The efficiency of L-NAME $\left(10^{-5} \mathrm{M}\right)$ at inhibiting nitric oxide synthase was confirmed by the suppression of acetylcholine-induced relaxation of phenylephrine $\left(10^{-5} \mathrm{M}\right)$-precontracted newborn and adult pulmonary arteries $(n=10)$.

Reproducibility of myogenic response. To evaluate the effect of repeated passive wall stress on the magnitude of the myogenic response, newborn and adult pulmonary artery segments were subjected to five consecutive stretches to $160 \%$ of their optimal length. The stretchinduced force was measured with the protocol previously described. After each stretch, the vessel segments were returned to their resting length, the Krebs-Henseleit solution was replaced, and a 10-min interval was allowed before the next stretch.

\section{RESULTS}

The vessel characteristics and smooth muscle mechanical properties of the newborn and adult guinea pig pulmonary artery are described in Table 1 . The newborn pulmonary arterial vessels had a significantly smaller diameter and muscle optimal length $(p<0.01)$. After supramaximal electrical and high potassium stimulation, stress was significantly lower in the newborn compared with the adult vessels $(p<0.01)$. Significant age differences were also observed for the vessel wall compliance, with the neonatal pulmonary arteries having lower values than their adult counterparts (Fig. 2).
Myogenic response. The myogenic response was consistently observed in $94 \%$ of the newborn and $93 \%$ of the adult pulmonary arterial segments. As illustrated in Figure 3 , the magnitude of the myogenic response varied according to age and the degree of stretch. An increase in optimal length by more than $120 \%$ consistently resulted in stretch-induced force of greater magnitude in the newborn compared with the adult $(p<0.01)$. The magnitude of the myogenic response was directly dependent on the degree of stretch in the newborn vessels, whereas in the adult, such a relationship only held for stretches up to $160 \%$ of their optimal length (Fig. 3).

Table 1. Vessel characteristics and muscle mechanical

\begin{tabular}{|c|c|c|}
\hline \multicolumn{3}{|c|}{ properties* } \\
\hline & Newborn & Adult \\
\hline Number of vessels & 45 & 30 \\
\hline Diameter in situ $(\mu \mathrm{m})$ & $1153 \pm 34$ & $1656 \pm 65 \dagger$ \\
\hline Width $(\mathrm{mm})$ & $1.64 \pm 0.06$ & $2.89 \pm 0.31 \dagger$ \\
\hline Thickness (mm) & $0.59 \pm 0.04$ & $0.64 \pm 0.06$ \\
\hline Resting length (mm) & $2.0 \pm 0.1$ & $4.1 \pm 0.3 \dagger$ \\
\hline \multicolumn{3}{|l|}{ Stress $\left(\mathrm{mN} / \mathrm{mm}^{2}\right)$} \\
\hline Electrical & $3.4 \pm 0.3$ & $5.6 \pm 0.4 \dagger$ \\
\hline $\mathrm{High}^{+}$ & $3.4 \pm 0.4$ & $5.8 \pm 0.7 \dagger$ \\
\hline
\end{tabular}

* Values are mean \pm SEM.

$\dagger p<0.01$ compared with the newborn.

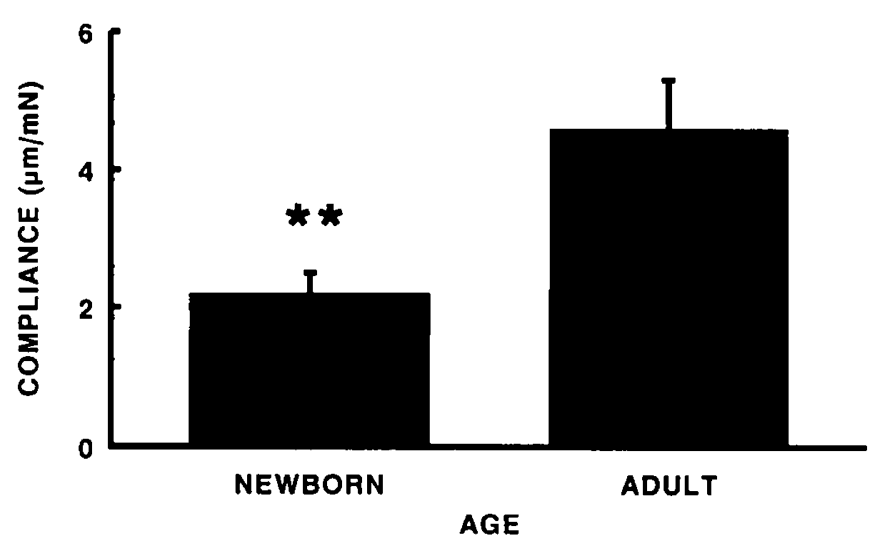

Figure 2. Pulmonary arterial wall compliance for the newborn $(n=20)$ and adult $(n=20)$ guinea pig. ${ }^{* *}, p<0.01$ compared with the adult. 


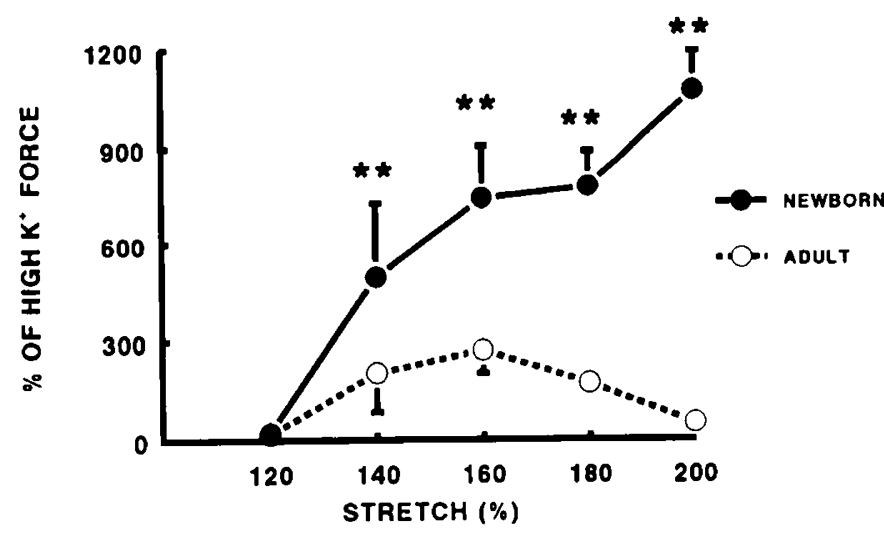

Figure 3. Magnitude of the myogenic response expressed as percent of force induced by $\mathrm{K}^{+}(127 \mathrm{mN})$ stimulation for the newborn $(n=20)$ and adult $(n=20)$ as percent stretch of the pulmonary arterial vessels' optimal length. ${ }^{* *}, p<0.01$ compared with the adult.

Repeated stretches. There were significant differences in the magnitude of myogenic response of vessels from different age groups to repeated intermittent stretches. Whereas the adult vessels responded to five intermittent repeated stretches with a consistent and reproducible myogenic response, in the newborn vessels no myogenic response was observed after the third stretch (Fig. 4).

Effect of pharmacologic agents. Addition of a calcium channel blocker (D-600) to the muscle bath suppressed the stretch-induced myogenic response (Fig. 5). In three newborn pulmonary arterial vessels, the stretch-induced force was $9.4 \pm 2.4 \mathrm{mN}$ before and $0 \pm 0$ after incubation with D-600 $(p<0.01)$.

The nitric oxide synthase inhibitor L-NAME did not alter the stretch-induced myogenic response (Fig. 6). After a $160 \%$ stretch, the newborn vessels $(n=3)$ generated a force of $10.7 \pm 2.6 \mathrm{mN}$ before and $9.1 \pm 1.0 \mathrm{mN}$ after $10^{-5} \mathrm{M}$ L-NAME $(p>0.05)$.

Indomethacin also had no effect on the myogenic response. The stretch-induced force in four newborn pulmonary arterial vessels was $10.4 \pm 1.7 \mathrm{mN}$ before and $10.9 \pm 3.7 \mathrm{mN}$ after indomethacin $\left(10^{-5} \mathrm{M}\right)$ incubation $(p$ $>0.05)$. In addition, indomethacin $\left(10^{-5} \mathrm{M}\right)$ did not alter the stress induced by high potassium stimulation. Stress was $3.1 \pm 0.7$ and $4.8 \pm 1.8 \mathrm{mN}$ before compared with 2.6

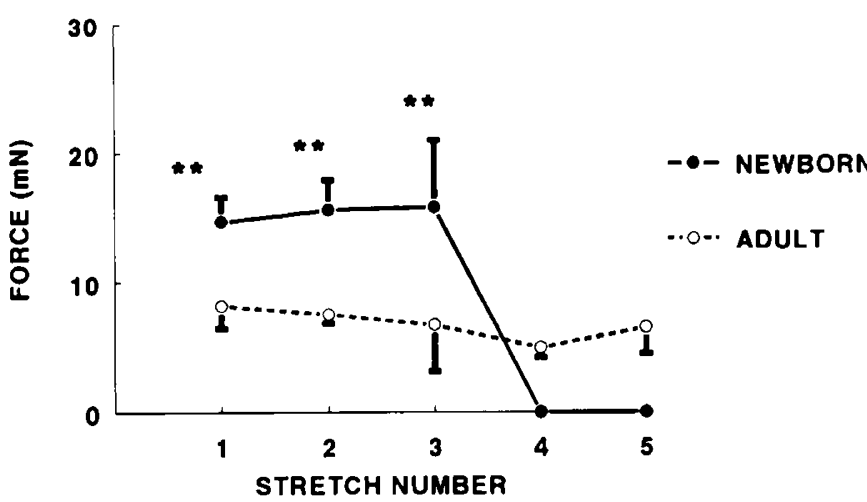

Figure 4. Effect of repeated stretches of $160 \%$ of optimal length for the newborn $(n=6)$ and adult $(n=6){ }^{* *}, p<0.01$ compared with the adult. \pm 0.5 and $4.5 \pm 1.7 \mathrm{mN}$ after indomethacin for the newborn $(n=6)$ and adult $(n=5)$ pulmonary vessel segments, respectively $(p>0.05)$.

\section{DISCUSSION}

Stretch-induced vasoconstriction has been reported in many organs of several animal species including humans $(2-4,6,7,11,12,23)$. It is predominant in small resistance arteries and believed to participate in the maintenance of basal vascular tone and autoregulation of capillary blood flow (2). The physiologic significance of the myogenic response in large capacitance vessels is presently unclear, but its existence has been demonstrated in several systemic arteries $(1,5,11,12)$ and veins (13). In the lung, the myogenic response has been poorly studied, and to the best of our knowledge the present data are the first to indicate the presence of stretch-induced force generation in large pulmonary arterial vessels.

Limitations of experimental approach. The measurement of the magnitude of the myogenic response in vitro is problematic and even more complex when developmental studies are considered. We have used the method previously described by Hwa and Bevan (3) to quantify the response. As evidenced by the force after relaxation with papaverine, it is clear that in almost all newborn and adult vessels a quick stretch induced muscle contraction. To enable us to compare the magnitude of the myogenic response in newborn and adult pulmonary arteries, we normalized the degree of wall stretch to their respective optimal lengths. This normalization method has been also used by Kulik et al. (9) to compare the myogenic response in lung vessels of different diameters.

We acknowledge that, given the age differences in vessel compliance and optimal length, for a given percentage increase in resting length the vessel wall stress may not be comparable in the newborn and adult vessels. The vessel wall tangential stress resulting from the stretch is directly proportional to the stretching load (equivalent to transmural pressure) and vessel radius, and inversely proportional to the wall thickness (24). The newborn vessels had on average a $50 \%$ smaller radius, lower compliance, and similar thickness compared with the adult. Thus, the vessel wall tangential stress for any given percent change in optimal length was similar for the two age groups.

In addition, the differences in stretch-induced force between the newborn and adult vessel segments for any degree of wall stretch over $120 \%$ of the vessel resting length were so great that age differences in the magnitude of the myogenic response are hard to refute. Last, age differences in the behavior of pulmonary large arteries to wall stretch are also evident. Whereas the adult vessels showed a maximum myogenic response after a $160 \%$ stretch, the newborn arteries showed progressively increasing responses when stretched up to $100 \%$ of their resting length.

Myogenic response of large pulmonary arteries. It is evident from the present data that the guinea pig extrapul- 


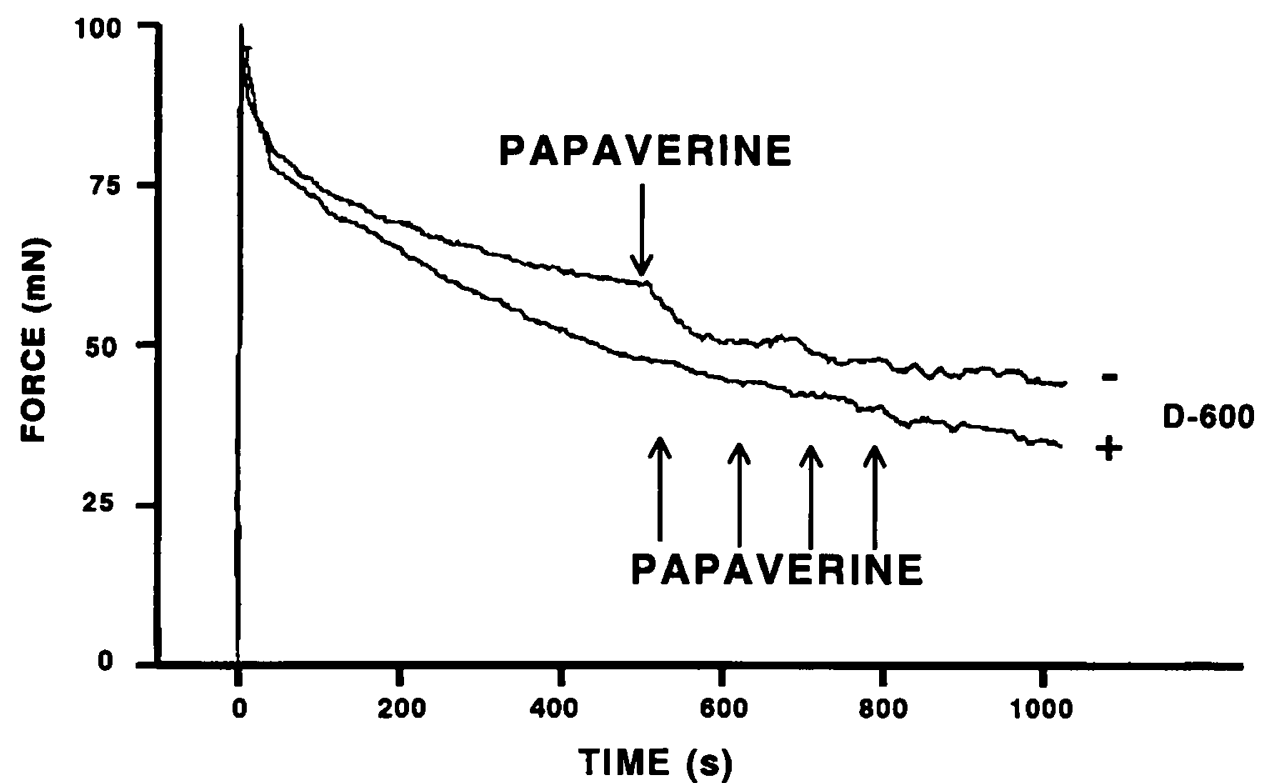

Figure 5. Representative tracings of stretch-induced contraction ( $160 \%$ of optimal length) with $(+)$ and without $(-)$ D- $600\left(10^{-5} \mathrm{M}\right)$. Note that the D-600 abolishes the myogenic response.

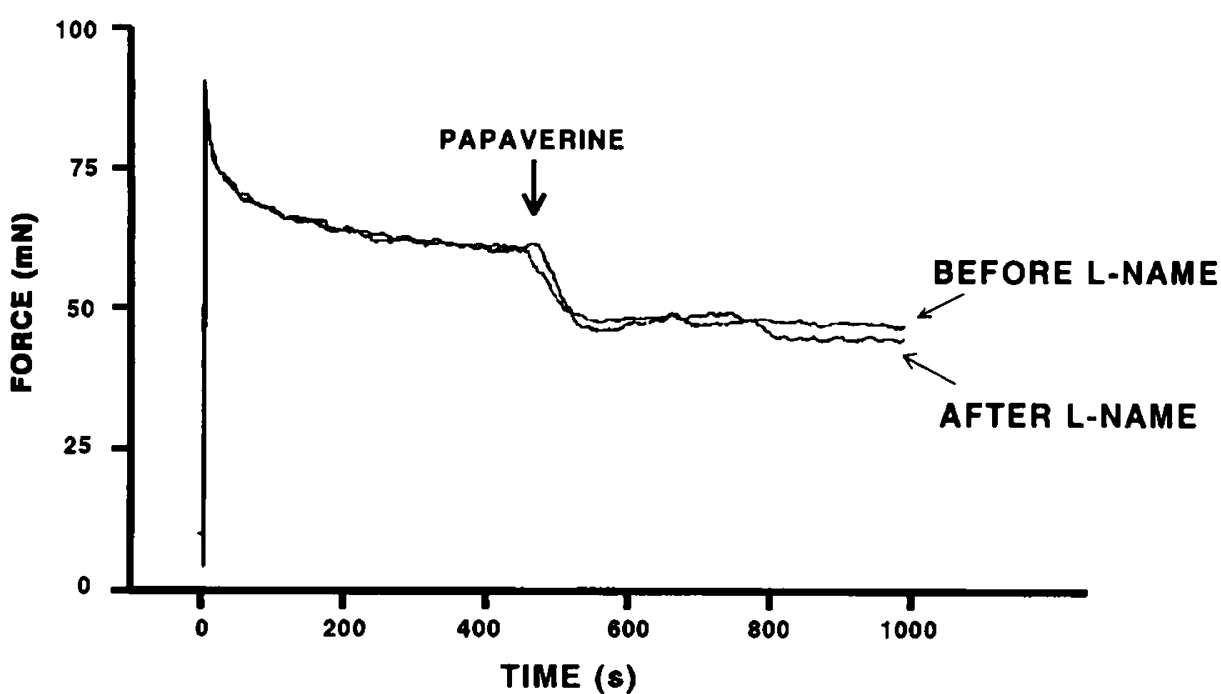

Figure 6. Representative tracing of stretch-induced contraction obtained in the same vessel segment of the newborn pulmonary artery before and after L-NAME $\left(10^{-5} \mathrm{M}\right)$. Note that L-NAME did not alter the myogenic response.

monary large capacitance arteries exhibit stretch-induced active force. In the newborn, for instance, the myogenic response elicited by stretching the vessel to $200 \%$ of its original resting length resulted in force generation 10 -fold greater than obtained after high potassium stimulation.

The presence of myogenic response in large systemic arteries has long been recognized (5). Bayliss (1) made his original observations of this response in the femoral artery of the rabbit in vivo and in the excised dog carotid artery. Stretch-induced force is also seen in the dog basilar artery $(10)$, the rabbit central ear artery $(11,12)$, and the human umbilical artery (25).

To the best of our knowledge, this is the first study to demonstrate stretch-induced force in large pulmonary arteries. Kulik et al. (9), studying the myogenic response of cat pulmonary arteries, were unable to observe stretch-induced force in vessels greater than $1000 \mu \mathrm{m}$ in diameter. The apparent discrepancy of their results with the present data may be related to the fact that Kulik et al. evaluated the myogenic response only in intrapulmonary arteries. Whether the myogenic response of large pulmonary vessels is limited to the extrapulmonary arteries is unclear from the present data because we did not evaluate the response of the intrapulmonary vessels of the guinea pig. Nevertheless, the myogenic responses of certain vessels vary across species (2), and it is conceivable that species differences may account for the differences between our results and those of Kulik et al. (9).

It is of interest that the magnitude of the myogenic response seen in the guinea pig large pulmonary artery was much greater than previously reported for cat small pulmonary arteries (9). A doubling of the optimal length in the $<1000-\mu \mathrm{m}$ arteries of the cat resulted in force generation equivalent to high potassium stimulation. In 
the guinea pig, after similar degrees of stretch, we observed a 10- and 6-fold increase in $\mathrm{K}^{+}$-stimulated force for the newborn and adult arteries, respectively. In the systemic circulation, such a magnitude of myogenic response has not been previously reported in large arteries, and the smaller resistance vessels are reputed as showing the greatest response (6). The magnitude of the myogenic response, however, is probably directly related to the vessel wall muscle mass, and differences between systemic and pulmonary large vessel wall composition may account for the present results. The medium of the main pulmonary artery consists of $80-90 \%$ smooth muscle (24). Compared with the aorta, the main pulmonary artery has a greater muscular/elastic ratio and has been shown to have the potential for active in vivo vasoconstriction (24). Thus, a myogenic response of greater magnitude is to be expected for the extrapulmonary arteries.

The characteristics of the stretch-induced force in the large pulmonary arteries of the guinea pig are similar to reported data from the smaller intrapulmonary arteries of the cat (9). The myogenic responses of large pulmonary arteries of the guinea pig were not affected by blockade of the nitric oxidase synthase, suggesting that the phenomenon is endothelium independent. The role of calcium in the myogenic response was clearly shown in both studies. D-600, a calcium channel blocker, abolished the response in the large arteries of the guinea pig, implying that the phenomenon is dependent on transmembrane calcium flux. Removal of calcium from the external medium suppressed the myogenic response of the small feline pulmonary arteries, indicating that the presence of a given extracellular calcium threshold is fundamental for force generation. A difference in response was found only for the indomethacin effect. In the guinea pig, indomethacin did not alter the myogenic response, whereas it blunted it in the feline small arteries. However, in the latter, as indicated by the authors, "indomethacin resulted in a general depression in muscle contractility suggesting that its effect may have been nonspecific." These similarities suggest that large extrapulmonary and small intrapulmonary arteries share a common mechanism of stretch-induced muscle contraction.

The physiologic significance of the myogenic response in large pulmonary arterial vessels is presently purely speculative. Large systemic veins such as the human saphenous vein have been shown to exhibit a myogenic response (13) that by virtue of altering wall stiffness and thus venous capacitance may contribute to the maintenance of cardiac output under physiologic conditions. Similarly, the large pulmonary arteries may participate in the control of vascular resistance downstream. Stretchinduced contraction of large pulmonary arteries may lead to an increase in wall stiffening, resulting in greater pressure transmission of the blood pulse wave to the smaller resistance vessels, where activation of the myogenic response would ultimately result in changes in pulmonary vascular resistance.
Stretch of the main pulmonary artery in vivo by means of a nonocclusive balloon has been previously reported to increase pulmonary vascular resistance downstream in dogs, sheep, and human infants $(15-18,21)$. These results have been refuted on the basis that the increase in pulmonary vascular resistance was caused by the balloon obstruction of one of the main pulmonary artery branches $(19,20)$. However, the fact that the pulmonary vascular resistance remains elevated in the newborn sheep for up to $2 \mathrm{~h}$ after deflation of the balloon (18) suggests that other mechanisms possibly involving stretch-induced increase in main pulmonary artery wall stiffness may have contributed to the pulmonary hypertension.

Developmental characteristics of myogenic response. Significant age differences in the myogenic response of large pulmonary arteries were observed in the guinea pig. For stretches greater than $120 \%$ of the optimal length, the newborn pulmonary arteries exhibited a significantly greater force than the adult. After repeated intermittent stretches, however, the myogenic response was abolished in the newborn, whereas the adult pulmonary vessels showed a consistent response for up to five stretches.

Aside from the study of human umbilical arteries (25), the myogenic response of systemic and pulmonary arteries has not been previously investigated in the immediate neonatal period. The present observation of increased stretch-induced force in the extrapulmonary arteries of the newborn guinea pig is in keeping with the greater increase in pressure in the newborn compared with the adult sheep after nonocclusive balloon distention of the main pulmonary artery (18). Given that the pulmonary vascular resistance in the immediate newborn period is higher than later in life, it is tempting to relate the myogenic response of pulmonary vessels to the basal vascular tone. Indeed, if changes in vascular resistance after main pulmonary artery stretch are related to the myogenic response, it is interesting to note that in human neonates the vascular response to nonocclusive balloon distention of the main pulmonary artery is dependent on the degree of pulmonary hypertension. Baylen et al. (21) have shown that the increase in pulmonary artery pressure distal to the balloon was greatest in patients with PPHN.

We have previously reported that the relaxation properties of the large pulmonary arteries are age dependent, with the newborn arteries having a longer relaxation time than the adult arteries (22). Pulmonary hypertension in the fetal sheep also results in prolongation of the vascular smooth muscle relaxation time (26). Thus, after main pulmonary artery balloon distention, the longer duration of pulmonary hypertension in the newborn sheep and the greater increase in pulmonary artery pressure in newborns with PPHN may be related to induction of the myogenic response and altered relaxation properties of pulmonary vascular smooth muscle.

Last, the significance of the age differences in the response to repeated intermittent passive stretches is not immediately clear. We have observed that the pulmonary artery smooth muscle poorly tolerates isotonic contrac- 
tions, with the newborn showing a significant decrease in shortening capacity after repeated electrical stimulation (unpublished data). It is conceivable that the inability of the newborn pulmonary artery to show a myogenic response past the third passive stretch is related to this poor tolerance to changes in length. Although we have not attempted to stretch the adult vessels by more than five times, in the adult feline pulmonary arterioles repeated stretches also resulted in lowering of the myogenic response (9).

In conclusion, the present study does demonstrate for the first time that large pulmonary arterial vessels exhibit stretch-induced force generation and that this response is greatest in the newborn. Given the possible physiologic significance, additional studies addressing the importance of the large vessels' myogenic response on the control of pulmonary vascular resistance are warranted.

\section{REFERENCES}

1. Bayliss WM 1902 On the local reactions of the arterial wall to changes of internal pressure. J Physiol (Lond) 28:220-231

2. Bevan JA, Laher 1 1991 Pressure and flow-dependent vascular tone. FASEB J 5:2267-2273

3. Hwa JJ, Bevan JA 1986 Stretch dependent (myogenic) tone in rabbit ear resistance arteries. Am J Physiol 250:H87-1495

4. Jackson PA, Duling BR 1989 Myogenic response and wall mechanics of arterioles. Am J Physiol 257:H1147-H1155

5. Johnson PC 1980 The myogenic response. In: Bohr D, Somlyo A, Sparks H (eds) The Handbook of Physiology. The Cardiovascular System. Vascular Smooth Muscle. Williams \& Wilkins, Baltimore, pp 4(1)9-442

6. Meininger GA, Davis MJ 1992 Cellular mechanisms involved in the vascular myogenic response. Am J Physiol 263:H647-H659

7. Mellander S, Arvidsson S 1974 Possible "dynamic" component in the myogenic vascular response related to pulse pressure distension. Acta Physiol Scand 90:283-285

8. Davis MJ, Gilmore JP, Joyner WL 1981 Responses of pulmonary allograft and cheek pouch arterioles in the hamster to alterations in extravalscular pressure in different oxygen environments. Circ Res 49:133-140
9. Kulik TJ, Evans JN, Gamble WJ 1988 Stretch-induced contraction in pulmonary arteries. Am J Physiol 255:H1391-H1.398

10. Katusic ZS, Shepherd JT, Vanhoutte PM 1987 Endothelial-dependent contraction to stretch in canine basilar arteries. Am J Physiol 252:H671-H673

11. Speden RN, Warren DM 1987 Myogenic adaptation of rabbit ear arteries to pulsatile internal pressures. J Physiol (Lond) 391:31.3-323

12. MacPherson RD, McLeod LJ, Rasiah RL 1991 Myogenic response of isolated pressurized rabbit ear artery is independent of endothelium. Am J Physiol 26():H779-H784

13. Berezi V, Greene AS, Dornyei G, Csengody J, Hodi G, Kadar A, Monos E 1992 Venous myogenic tone: studies in human and canine vessels. Am J Physiol 263:H315-H320

14. Best CH, Taylor NB 1991 Physiological Basis of Medical Practice. Williams \& Wilkins, Baltimore, pp $118-119$

15. Laks MM, Juratsch CE, Garner D, Beazell J, Criley JM 1975 Acute pulmonary artery hypertension produced by distention of the main pulmonary artery in the conscious dog. Chest $68: 807-813$

16. Juratsch CE. Jengo JA, Laks MM 1977 Role of the autonomic nervous system and pulmonary artery receptors in production of experimental pulmonary hypertension. Chest 71 (suppl):265-269

17. Juratsch CE, Jengo JA, Castagna J, Laks MM 1980 Experimental pulmonary hypertension produced by surgical and chemical denervation of the pulmonary vasculature. Chest 77:525-530

18. Juratsch CE, Emmanouilides GC, Thibeault DW, Baylen BG, Jengo JA, Laks MM 1980 Pulmonary arterial hypertension induced by distention of the main pulmonary artery in conscious newborn, young, and adult sheep. Pediatr Res $14: 1.332-1.338$

19. Lloyd Jr TE 1986 Pulmonary arterial distension does not cause pulmonary vasoconstriction. J Appl Physiol 61:741-745

20. Lloyd Jr TC, Juratsch CE 1986 Pulmonary hypertension induced with an intra-arterial balloon: an alternate mechanism. J $A$ ppl Physiol 61:746-751

21. Baylen BG, Emmanouilides GE, Juratsch CE, Yoshida Y. French WJ, Criley JM 1980 Main pulmonary artery distention: a potential mechanism for acute pulmonary hypertension in the human newborn infant. J Pediatr 96:540-544

22. Belik J, Stephens NL 1993 Developmental differences in vascular smooth muscle mechanics in pulmonary and systemic circulations. J Appl Physiol $74: 682-687$

23. Johnsson E, Folkow B, Karlstrom G 1991 Myogenic responsiveness in rat hindquarter vessels during constant-flow and constant-pressure perfusion in vitro: effects of various potassium concentrations and of endothelial nitrous oxide blockade. Acta Physiol Scand 142:319-32x

24. Somlyo AV, Somlyo AP 1964 Vasomotor function of smooth muscle in the main pulmonary artery. Am J Physiol 206:1196-1200

25. Sparks HV 1964 Effecl of quick stretch on isolated vascular smooth muscle. Circ Res XIV and XV(suppl I):1-25+1-260)

26. Belik J, Halayko AJ, Rao K, Stephens NI. 1993 Fetal ductus arteriosus ligation. Circ Res 72:588-596, 